\title{
The role of redox buffering by electron donors in mediating the behaviour of metals in sediments under aerobic conditions
}

\author{
LAURA NEWSOME ${ }^{1,3}$, AGUSTÍN SOLANO ARGUEDAS ${ }^{2,3}$, \\ JONATHAN R. LLOYD ${ }^{3}$ \\ ${ }^{1}$ Camborne School of Mines, University of Exeter, Penryn, \\ TR109FE, UK, 1.newsome@exeter.ac.uk \\ ${ }^{2}$ Unidad de Recursos Forestales, Universidad de Costa Rica, \\ San José, Costa Rica, agustin.solano@ucr.ac.cr \\ ${ }^{3}$ Williamson Research Centre, University of Manchester, \\ Manchester, M13 9PL, UK, jon.lloyd@manchester.ac.uk
}

In typical biostimulation experiments an electron donor is added to sediment microcosms to stimulate microbiallymediated terminal electron accepting processes, leading to the development of reducing conditions. The results of such experiments demonstrated the reductive immobilisation of contaminant metals such as uranium and technetium, either by direct enzymatic processes or via sequestration as iron(II) or sulfide minerals. Alternatively, metals that were associated with manganese(IV) or iron(III)-oxides such as arsenic, cobalt and nickel were released to the aqueous phase as a result of microbial metal reduction.

To investigate the fate of these metals under oxidising conditions, aeration experiments may be performed, during which the reduced sediment is subjected to highly oxidising conditions, and metal behaviour is expected to be the opposite of the biostimulation experiments. In fact, the results of a series of reoxidation experiments showed that the presence of residual electron donor is the key factor that controls the behaviour of metals in these sediment systems. For example, oxidative remobilisation of technetium was limited in the presence of slow-release substrates or zero valent iron. The oxidative remobilisation of uranium by nitrate only occurred when the residual electron donor had been completely metabolised. Cobalt, nickel and manganese remained in solution following the aeration of a cellulose biostimulation experiment for five months.

Together these results indicate that the presence of residual electron donor plays a key role in limiting the expected oxidation of metals, even under conditions that would be considered to be highly oxidising (e.g. by Eh measurements). This buffering capacity may be due to sediment microbial communities continuing to oxidise the residual electron donor coupled to oxygen or nitrate reduction. Alternatively, the abiotic oxidation of residual zero valent iron may offer a similar protective effect. 